\title{
Effect of family disintegration on age at menarche
}

\author{
Alma Toromanović ${ }^{1^{*}}$, Husref Tahirović ${ }^{2}$, Collaborators from pediatric centers in \\ Federation of Bosnia and Herzegovina ${ }^{3}$
}

${ }^{1}$ Department of Pediatrics, University Clinical Center Tuzla, Tuzla, Bosnia and Herzegovina, ${ }^{2}$ Academy of Sciences and Arts of Bosnia and Herzegovina, Sarajevo Bosnia and Herzegovina, ${ }^{3}$ Appendix

\footnotetext{
${ }^{*}$ Corresponding author: almatoromanovic@bih.net.ba

Tel.: + 38735303715

Fax.: + 38735303730
}

Received: 16 November 2015

Accepted: 30 November 2015

Key words: Age at menarche - Family disintegration - Psychosocial factors • Familial stress - Federation of Bosnia and Herzegovina.

\begin{abstract}
Objective. The aim of this study was to determine the effect of psychosocial factors on the age at menarche of girls in Federation of Bosnia and Herzegovina (FBH). Subjects and methods. A cross-sectional study was conducted from September 2002 to May 2003 in all Cantons of the FBH. The random stratified sample included 19.803 girls aged 9.0 to 17.5 years. Data were collected using the status quo method. Probit analysis was used to estimate median age at menarche and $95 \%$ confidence intervals. Results. The present study shows that menarche occurred significantly earlier $(\mathrm{p}<0.05)$ in girls from dysfunctional families (median: 12.99 years, $95 \%$ confidence interval: $12.93-13.05$ ) than in girls who grew up in intact families (median: 13.04 years, $95 \%$ confidence interval: 13.01-13.07). Analyzing separately the impact of each of family stressors on age at menarche, we found that menarcheal age was significantly lower in girls from single-mother families, whose parents are divorced, whose one parent is died and where alcoholism in family is present than in girls from intact families. Maturation was found to be earlier in girls from dysfunctional families then in those from intact families after the influence of place of residence and sibship size was eliminated. Conclusion. From our research we can conclude that the girls from dysfunctional families reached earlier age at menarche than their peers who grew up in normal families, and that this effect did not disappear after controlling for socioeconomic variables.
\end{abstract}

\section{Introduction}

Pubertal maturation is a complex physical process accompanied by major social and cognitive changes. This biological event is the outcome of a number of social and biological factors. The timing of puberty is influenced by genetics (1), socioeconomic status, environmental toxins, exercise, diet, weight, and the presence of chronic illness and stress (2). The relationship between stress and pubertal timing is especially intriguing. Whereas high levels of chronic and severe stress (e.g. nutritional deprivation, extreme exercise), as well as the events related to war $(3,4)$ are associated with delayed pubertal onset, a recent studies demonstrated that psychosocial factors such as familial/parental instability, family conflict, father absence, and lack of a traditional twoparent family structure are associated with an earlier menarche in girls $(5,6)$.

Draper and Harpending (7) have proposed a hypothesis that early family experiences shape the reproductive strategy which individuals will follow in later life. Whereas 
father-absent girls develop behaviour profiles consistent with an expectation that paternal investment in childrearing will not be forthcoming and that pair bonds will not be enduring, those from father-present households develop as if anticipating the opposite, deferring sexual activity once they reach biological maturity while seeking to establish and maintain enduring, close, heterosexual relationships. This has been advances further by Belsky et al. (5) who have proposed a life history model of the role of psychosocial stressors in accelerating timing of puberty in girls. Also they theorized that humans have evolved to be sensitive to specific faetures of their early childhood environments, and that exposure to different environments biases children toward the development of different reproductive strategies. Children whose experiences in and around their families of origine are characterized by relatively high levels of stress (father absence, negative family relationships, lack of positive and supportive family relationships) are hypothesized to develop in a manner that speeds rates of pubertal maturation, accelerates sexual activity, and orients the individual toward relatively unstable pair bonds. Furthermore, they suggested that it was relatevely early family experiences - in the first 5-7 years of life - that shape reproductive strategy. The influence of an early family conflict and stress on acceleration of pubertal maturation has been observed by many authors, but only after the appearance of the psychosocial acceleration theory (5) its importance was emphasized. A number of studies have supported this hypothesis showing that early family disruption and separation from the father, is associated with earlier menarche (8-14).

An implication of Belsky et al. (5) model is that father-absent effects on daughters' pubertal timing should involve more than just father-absent effects; that is, quality of paternal investments should predict daughters' pubertal timing even within father-present homes. The quality of paternal care is believed to affect sexual development independent of other stressors that may be present in the family system. Parental warmth, positive family relationships, and paternal involvement in child rearing are related to a comparatively later age of menarche (15, 16). Father-daughter relationships are particularly predictive of menarche timing, and the quality of the father-daughter relationship is more strongly associated with rate of physical maturation than the quality of the mother-daughter relationship (15). More time spent by the father in child care, greater father-daughter affectionate-positivity during the early years was associated with later pubertal timing (15).

It seems that father-absent effects on pubertal timing is different from more general effects of interpersonal stress on pubertal maturation. Although mother absence is at least as stressful as father absence, it does not appear to have the same effect to daughters' pubertal timing. Mekos et al. (17) found that years of father absence but not years of mother absence had an accelerating effect on girls' pubertal maturation. Surbey (18) found that girls who grew up in fatherabsent homes, but not those from motherabsent homes, experienced earlier menarche than girls who grew up with both parents present.

What is the mechanism underlying earlier pubertal timing in girls in father-absent homes? It was hypothesized that exposure to unrelated adult males, especially stepfathers or mothers' dating partners would be associated with earlier pubertal maturation in girls. Research on a variety of mammalian species indicates that exposure to pheromones produced by unrelated adult male conspecifics accelerates female pubertal maturation (19). Research on humans has also provided definitive evidence of regulation of women's reproductive functioning by pheromones 
(20). If human females possess physiological mechanism that accelerate pubertal maturation in response to pheromonal stimulation by unrelated adult males, then exposure to stepfathers and mother's dating partners, rather than absence of the biological father per se, should more strongly predict early pubertal timing in girls. This hypothesis is consistent with data reported by Mekos et al. (17) showing that girls in stepfather-present homes experienced faster pubertal growth than girls in single-mother homes. Consistent with this prediction, there was a significant correlation between age of daughter when an unrelated father figure first came into her life and timing of pubertal maturation. The younger the daughter at the time of the father figure's arrival, the earlier her pubertal timing (21). These results highlight a potentially important role for unrelated adult males in regulating timing of pubertal maturation in girls.

Most research on the genetic origins of menarche has been conducted using only female relatives. However, there may be paternal as well as maternal influences on age of menarche. In fact, the same genetic factors that influence fathers' likelihood to abandon marriages may contribute to an earlier age of menarche in their daughters. Shorter alleles of the X-linked androgen receptor (AR) gene are associated with aggression, impulsivity, high number of sexual partners, and divorce in males and with early age of menarche in females. These findings support a genetic explanation of the Belsky psychosocial evolutionary hypothesis regarding the association of fathers' absence and parental stress with early age of onset of menarche and early sexual activity in their daughters (22).

The aim of this study was to analyse the effect of several family stressors on the age at menarche of girls in Federation of Bosnia and Herzegovina, after controlling for socioeconomic factors which influence matu- ration greatly in developing countries and mask the impact of psychosocial factors.

\section{Subjects and methods}

\section{Demographic data}

Bosnia and Herzegovina $(\mathrm{BH})$ is located in Southeastern Europe, covering totally $51,209.2 \mathrm{~km}^{2}$, with a population of $3,791,622$ inhabitants (23). The country is divided on two entities: Federation of Bosnia and Herzegovina (FBH) and Republica Srpska. The FBH consists of 10 federal units-cantons with a population of $2,371,603$ inhabitants (23).

The BH Gross Domestic Product (GDP) total in 2003 was 7.09 billion US dollars, and the GDP per capita was 1852 US dollars, while the average net monthly salary was 524.18 BAM (288.26 US dollars using the current exchange rate) (24). In December 2003, the unemployment rate in $\mathrm{FBH}$ has been high, $44.01 \%$ (25).

\section{Methods, participants and data collection}

A cross-sectional study was conducted from September 2002 to May 2003 in all Cantons of the FBH. A total of 19.803 girls aged 9.0 to 17.5 years from eighty primary and thirty seven secondary schools were chosen at random from a stratified cross-sectional sample. The data used in the present study were obtained by questionnaires which provided: examination date, data and place of birth, place of residence, family size, parents' educational level, data about menarche was collected by the status quo method by a investigator who asked the girls whether or not their menarche had occurred. For family size, three categories were identified: 1,2 , and 3 children in the family. Place of residence during childhood was classified into two categories: rural and urban places. Girls were classified according to the level of 
parental education into four categories: university, high school, vocational school, and elementary school. Family disintegration was assessed taking into account the following stress variables: a single-mother family, divorce or separation of the parents, death of one or both parents, parental prolonged illness, and alcoholism of one or both parents. On the basis of the data from the questionnaires, the girls were divided into two groups. The girls who lived in functional families were included in the group categorized as "Intact family", and girls who listed some of family stressors were included in the group denoted as "Dysfunctional family". Data were collected using the status quo method.

\section{Statistical analysis}

Probit analysis was used to estimate median age at menarche and 95\% confidence intervals using the Probit procedure of SAS Software, version 9.00 (SAS Institute Inc., Cary, NC, USA). The statistical significance of the differences between groups was evaluated by the Student's $t$-test. A difference was considered significant when $\mathrm{p}<0.05$.

\section{Results}

The average age at menarche of girls from families with some of childhood stressors was compared with those of girls from functional families, to establish whether girls with an experience of family stress did in fact experience menarche at an earlier age. Indeed, this study shows that menarche occurred significantly earlier $(\mathrm{p}<0.05)$ in girls from dysfunctional families (median: 12.99 years, 95\% confidence interval: 12.93-13.05) than in girls belonging to intact families (median: 13.04 years, $95 \%$ confidence interval: 13.01-13.07). The median age at menarche for all FBH girls was 13.02 years (12.9913.05, 95\% CI) (26).

Analyzing separately the impact of each of family stressors on age at menarche, we found that menarcheal age was significantly lower in girls from single-mother families, whose parents are divorced, whose one parent is died and where alcoholism in family is present than in girls from intact families. In contrast, menarcheal age of girls who reported long-standing parental illness was higher, but did not differ significantly from those in intact families (Table 1).

After controlling for sibship size (twochildren families), we found the similar results (Table 2). In girls from single-mother families, whose one parent is died, and whose parent is alcoholic menarche still occurred significantly earlier than in girls from intact families. Furthermore, girls whose parents are divorced also had an earlier age at menarche than girls raised in intact families, but difference was not significant. How-

Table 1 Age at menarche of girls according to the family stressors

\begin{tabular}{llll}
\hline Variable & $\mathrm{n}$ & Median & $95 \% \mathrm{Cl}$ \\
\hline Single-mother & 2196 & $12.93^{*}$ & $12.84-13.02$ \\
Divorced parents & 872 & $12.96^{*}$ & $12.81-13.10$ \\
Death of one parent & 2026 & $12.98^{*}$ & $12.88-13.07$ \\
Death of both parents & 33 & - & - \\
Long-standing parental illness & 1845 & $13.05^{\dagger}$ & $12.95-13.15$ \\
Alcoholic & 544 & $12.94^{*}$ & $12.73-13.17$ \\
Intact & 14953 & 13.04 & $13.01-13.07$ \\
\hline
\end{tabular}

$\mathrm{Cl}=$ Confidence interval; ${ }^{*} \mathrm{p}<0.05 ;{ }^{\dagger} \mathrm{p}>0.05$ compared to intact family. 
ever, even when the number of children in the family was held constant, menarcheal age was still higher in girls who reported long-standing parental illness compared to those from intact families.

When the size of the family was eliminated (Table 3) we found that girls growing up in dysfunctional families with one child and two children had earlier menarche than girls who were not exposed to such dysfunction. In contrast, in families with three children menarche occurred later in girls from dysfunctional families compared to those from intact families. In all three groups difference was not significant.
The group of single-mother families was the largest among the dysfunctional families and this group was selected for comparison with intact families independent of the family size which is among the most important socio-economic factors influencing on the age at menarche. Table 4 shows that girls in the groups of single-mother families with one child and two children had menarche significantly earlier compared to those from intact families. However, as in the full sample girls raised in single-mother families with three children tended to experience later menarche than girls raised in intact families, and difference was not significant.

Table 2 Age at menarche of girls from two-children families according to the family stressors

\begin{tabular}{llll}
\hline Variable & $\mathrm{n}$ & Median & $95 \% \mathrm{Cl}$ \\
\hline Single-mother & 1010 & $12.85^{*}$ & $12.72-12.99$ \\
Divorced parents & 628 & $12.87 \dagger$ & $12.69-13.04$ \\
Death of one parent & 1264 & $12.83^{*}$ & $12.71-12.95$ \\
Death of both parents & - & - & - \\
Long-standing parental illness & 967 & $12.96^{+}$ & $12.82-13.10$ \\
Alcoholic & 241 & $12.74^{*}$ & $12.41-13.02$ \\
Intact family & 7487 & 12.95 & $12.90-12.99$ \\
\hline
\end{tabular}

$\mathrm{Cl}=$ Confidence interval; ${ }^{*} \mathrm{p}<0.05 ;{ }^{\dagger} \mathrm{p}>0.05$ compared to intact family.

Table 3 Age at menarche of girls from dysfunctional and intact families by family size

\begin{tabular}{lllllll}
\hline \multirow{2}{*}{$\begin{array}{l}\text { Number of children } \\
\text { in the family }\end{array}$} & \multicolumn{3}{c}{ Dysfunctional family } & \multicolumn{3}{c}{ Intact family } \\
\cline { 2 - 7 } & $\mathrm{n}$ & Median & $95 \% \mathrm{Cl}$ & $\mathrm{n}$ & Median & $95 \% \mathrm{Cl}$ \\
\hline 1 & 740 & $12.72^{*}$ & $12.57-12.86$ & 864 & 12.81 & $12.66-12.95$ \\
2 & 2140 & $12.91^{*}$ & $12.81-13.0$ & 7487 & 12.95 & $12.90-12.99$ \\
3 & 1967 & $13.18^{*}$ & $13.08-13.29$ & 6597 & 13.17 & $13.12-13.22$ \\
\hline
\end{tabular}

$\mathrm{Cl}=$ Confidence interval; ${ }^{*} \mathrm{p}>0.05$ compared to intact family.

Table 4 Age at menarche of girls from single-mother and intact families by family size

\begin{tabular}{lllllll}
\hline \multirow{2}{*}{$\begin{array}{l}\text { Number of children } \\
\text { in the family }\end{array}$} & \multicolumn{5}{l}{ Single-mother family } & \multicolumn{5}{l}{ Intact family } \\
\cline { 2 - 7 } & $\mathrm{n}$ & Median & $95 \% \mathrm{Cl}$ & $\mathrm{n}$ & Median & $95 \% \mathrm{Cl}$ \\
\hline 1 & 455 & $12.66^{*}$ & $12.47-12.84$ & 864 & 12.81 & $12.66-12.95$ \\
2 & 1010 & $12.85^{*}$ & $12.72-12.99$ & 7487 & 12.95 & $12.90-12.99$ \\
3 & 729 & $13.24^{+}$ & $13.06-13.40$ & 6597 & 13.17 & $13.12-13.22$ \\
\hline
\end{tabular}

$\mathrm{Cl}=$ Confidence interval; ${ }^{*} \mathrm{p}<0.05 ;{ }^{\dagger} \mathrm{p}>0.05$ compared to intact family. 
Table 5 Age at menarche of girls from two-children dysfunctional and intact families by place of residence

\begin{tabular}{lllllll}
\hline \multirow{2}{*}{ Place of residance } & \multicolumn{5}{c}{ Dysfunctional family } & \multicolumn{5}{l}{ Intact family } \\
\cline { 2 - 7 } & $\mathrm{n}$ & Median & $95 \% \mathrm{Cl}$ & $\mathrm{n}$ & Median & $95 \% \mathrm{Cl}$ \\
\hline Urban & 1531 & $12.72^{*}$ & $12.62-12.83$ & 4082 & 12.81 & $12.75-12.88$ \\
Rural & 1340 & $13.00^{\dagger}$ & $12.88-13.12$ & 4261 & 13.05 & $12.98-13.11$ \\
\hline
\end{tabular}

$\mathrm{Cl}=$ Confidence interval; ${ }^{*} \mathrm{p}<0.05 ;{ }^{\dagger} \mathrm{p}>0.05$ compared to intact family.

Table 6 Age at menarche of girls from dysfunctional and intact families by parent's level of education

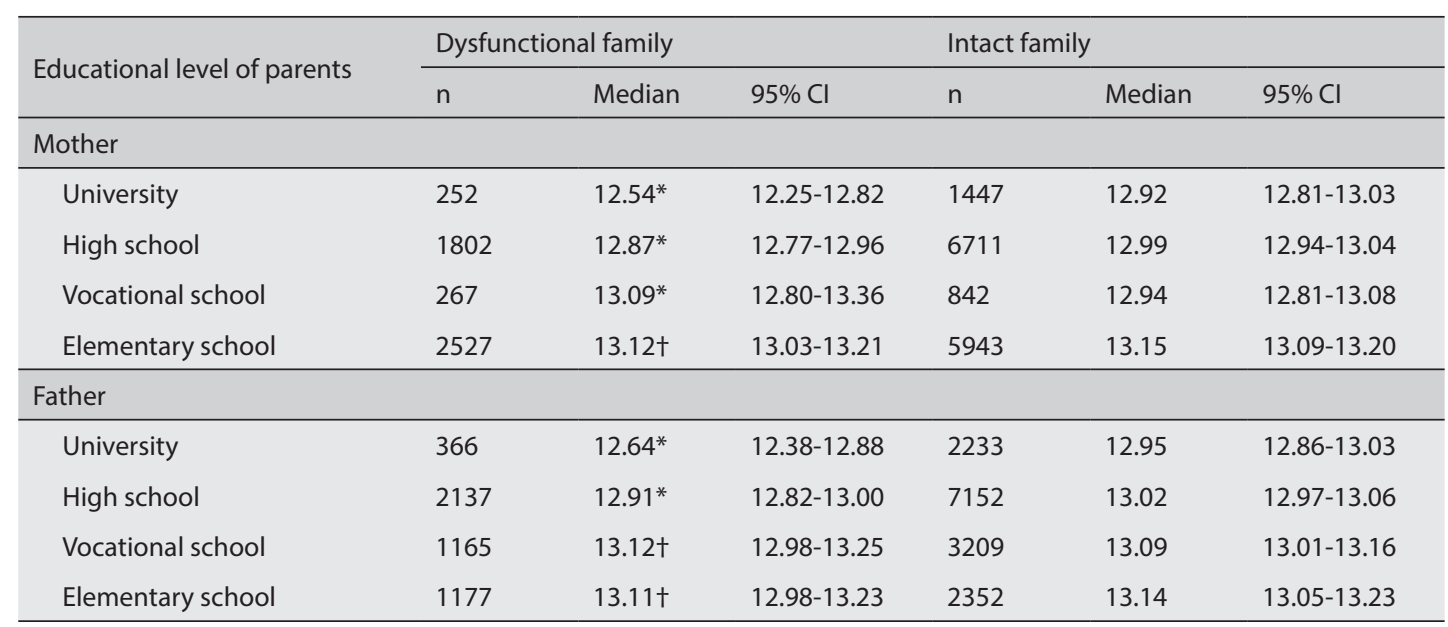

Confidence interval ${ }^{*} \mathrm{p}<0.05 ;{ }^{\dagger} \mathrm{p}>0.05$ compared to intact family.

Table 5 presents data on the comparison between the median age at menarche of girls from dysfunctional and intact families independent of sibship size (two-children families) and place of residence. After adjusting for these variables, we found that girls who lived in urban places and raised in two-children dysfunctional families had significantly earlier age at menarche than girls raised in two-children intact families. Menarcheal age of girls from rural places raised in dysfunctional families was lower, but did not differ significantly from those in intact families.

The results presented in Table 6 show that girls from dysfunctional families whose parents (mother or father) had a university- and high school level of education had significantly earlier age at menarche than girls from intact families. Age at menarche occurred earlier also in girls from dysfunctional families whose parents (mother or father) had elementary school degree compared to those from intact families, but difference was not significant. In contrast, girls from dysfunctional families whose parents (mother or father) had a vocational school degree had later age at menarche than girls from intact families, and difference was significant in group of girls whose mothers had this educational level.

\section{Discussion}

The aim of this study was to evaluate the impact of several family stressors on age at menarche of girls in Federation of Bosnia and Herzegovina. We hypothesized that girls from dysfunctional families, when compared to those from intact families would have earlier age at menarche. The present study indicates that girls from dysfunctional families experienced earlier age at menarche than girls who grew up in intact families. 
This is consistent with other studies which have shown that father absence and early family conflict and stress are associated with earlier menarche (10, 18, 21, 27-31).

Our results have shown that age at menarche occurred significantly earlier in group of girls from single-mother families, compared to those from intact families. These data are consistent with many other studies showing that girls growing up in fatherabsent homes mature earlier than do other girls $(9,10,12,15,21,27-29,32)$. Moreover, meta-analysis of Webster et al. (14) showed that father absence was significantly related to earlier menarche. Single parenthood may involve consequence other than father absence, specifically those of financial hardship, low social status and lack of social support. Indeed, in an analysis of four representative samples of US single-mother families, it was found that the single most important factor contributing to the difficulties experienced by children of lone parents in later life was the lower family income associated with single parenthhood (33). It is possible, however, that other pressures on these mothers such as social stigma and lack of social support may interfere with their parenting role and leave their children vulnerable to emotional problems. Weinraub (34) found that children of these mothers had more behavioural problems, poorer school performance than children from two-parent families. These negative outcomes were found to be associated with the low maternal social support and maternal stress experienced by some of the solo mothers, rather than directly related to single parenthood. In the study by Dunn et al. (35) greater maternal negativity toward the child was shown by single mothers than by mothers in two-parent heterosexual families, and found to be associated with a higher rate of behavioural problems in children. McLanahan and Sandefur (33) reported that single mothers exert less control over their children in terms of supervi- sion and establishing rules than do mothers in two-parent families. The poorer quality of parenting shown by single mothers may be explained, in part at least, by the higher rates of psychological problems, particularly depression, found among single mothers. Depression is thought to interfere with parent's emotional availability and sensitivity to their children and also with their control and discipline of them (36).

Consistent with the previous research $(26,32)$, our girls whose parents are divorced had significantly earlier age at menarche than girls from intact families. These children are confronted with a series of negative events rather than a single experience. Since small procent of divorced women remarry, the economic situation of children after divorce of the parents is generally very similar to that of single-mother families. In all such cases the mother has to provide for the family and so has little time for the children who are often left at home without anybody's control. Divorce is widely viewed as a stressful life event. The most influential factor seems to be the exposure to parental conflict, which was found in a review by Amato (37) to be the most significant predictor of emotional distress in the children of divorced parents. Divorce also create adjustment difficulties for mothers, who may have raised level of depression and anxiety (38).

Girls reared in families where one or both parents are alcoholic reached menarche earlier than their peers reared in normal families, and these data are consistent with studies done in Poland $(32,39)$. Stressful interpersonal relationships ocurring in the family where one or both parents are alcoholic predict earlier pubertal timing in the daughter.

Menarcheal age of our girls who reported long-standing parental illness was higher than those in girls from intact families, and this was the case even when the number of children in the family was held constant. The 
extent of family disruption depends on the seriousnes of the illness, the family's level of functioning before the illness, and socioeconomic considerations. In some instances, a major illness brings a family closer together; in others, even a minor illness causes significant strain. Long-term illness, even in the most stable and supportive families brings changes in family relationships. We can speculate that long-term illness in our sample decreases the socio-economic status of the family to such an extent that maturation of daughters was delayed compared to intact families, or that positive family relationships, lack of parental conflict in childrearing are related to later age of menarche.

The most obvious difficulty confronting a researcher is the presence of a number of socio-economic factors, such as urban/rural residence, family size, educational level of parents, which influence maturation greatly and mask the impact of psychosocial factors (40-42). Toromanović and Tahirović (43) have examined the effect of socioeconomic status on the age at menarche of girls in $\mathrm{FBH}$ and found that maturation in girls is heavily influenced by very significant inequalities in social and economical conditions in the region. This is the reason why most of the studies presented pay special attention to comparing ages at menarche of girls from dysfunctional families with those from normal families with comparable socio-economic levels. Results of our study showed that even after adjusting for these variables, girls from dysfunctional families had earlier menarche than girls from intact families.

When the size of the family was eliminated we found that girls growing up in dysfunctional families with one child and two children had earlier menarche than girls who were not exposed to such dysfunction. In contrast, in dysfunctional families with three children the low standard of living prevails in delaying maturation.
The present study showed that girls in the groups of single-mother families with one child and two children had menarche significantly earlier compared to those from intact families independent of the family size. However, the third child in a single-mother families decreases its socio-economic status to such an extent that maturation of daughters was delayed compared to intact families. These data are consistent with the study by Hulanicka (32).

In addition, maturation was found to be earlier in girls from dysfunctional families then in their peers who grew up in intact families after the influence of place of residence and sibship size was eliminated. The influence of family disintegration on age at menarche is evident independent of parental educational level with girls reared in dysfunctional families reached menarche earlier than their peers reared in normal families. We can not explain why girls from dysfunctional families whose parents (mother or father) had a vocational school degree had later age at menarche than girls from intact families, since girls whose parents have lower degree of educational level had earlier age at menarche than their peers from intact families. We may speculate that in this group the standard of living was so low causing the delay in maturation of daughters compared to those in intact families.

\section{Limitations of the research}

Although this study had a number of strengths (e.g. national sample, the evaluation of the effect of psychosocial stressors on the age at menarche after controlling for socioeconomic variables), it also has a number of limitations. The exact time or the duration in childhood when father absence occurred was not specified. Furthermore, the presence of the psychological problems, particularly depression in mothers, an exposure of girls to unrelated adult males, especially 
stepfathers or mothers' dating partners, and the quality of the family relationships, especially the father-daughter relationships were not investigated.

\section{Conclusion}

The present study indicates that girls from dysfunctional families experienced earlier age at menarche than their peers who grew up in normal families supporting for the evolutionary model of pubertal timing linking stressful family environments to earlier puberty in girls. Comparing ages at menarche of girls from dysfunctional families with those of girls from normal families with comparable socio-economic levels we have eliminated the effect of socio-economic factors, which influence maturation greatly and mask the impact of psychosocial factors.

\section{What is already known on this topic}

These data are consistent with past research showing that family conflict and father absence contribute to the prediction of menarcheal age.

\section{What this study adds}

Comparing ages at menarche of daughters from dysfunctional families with those of daughters from normal families with comparable socio-economic levels we have eliminated the effect of socio-economic factors, which influence maturation greatly and mask the impact of psychosocial factors.

Acknowledgments: We thank the colleagues in pediatric centers across FBH for their valuble support of this project.

Apendix. Collaborators from pediatric centers in Federation of Bosnia and Herzegovina: Željka Bilinovac, Clinical Hospital Mostar; Zoran Budimić, Health Center Orašje; Emilija Denjo, Cantonal Hospital Mostar; Sabrija Džanović, Cantonal Hospital Goražde; Aida Filipović; Institute of Public Health of Federation of Bosnia and Herzegovina; Izet Hadžimujić, Cantonal Hospital Travnik; Rusmira Konjević, Cantonal Hospital Bihać; Glorija Lijović, Cantonal Hospital Livno; Dijana Štimljanin-Koldžo, Cantonal Hospital Zenica.
Authors' contributions: Conception and design: AT, HT; Acquisition, analysis and interpretation of data: AT, HT; Drafting the article: AT; Revising it critically for important intellectual content: HT.

Conflict of interest: The authors declare that they have no conflict of interest.

Funding: The study was supported by a grant from the Federal Ministry of Education and Science (0439-8310-1/01), Stjepana Radića 33, Mostar, Bosnia and Herzegovina.

\section{References}

1. Van den Berg SM, Boomsma DI. The Familial Clustering of Age at Menarche in Extended Twin Families. Behav Genet. 2007;37:661-7.

2. Yermachenko A, Dvornyk V. Nongenetic Determinants of Age at Menarche: A Systematic Review. Biomed Res Int. 2014;2014:1-14.

3. Tahirović HF. Menarchal age and the stress of war: an example from Bosnia. Eur J Pediatr. 1998;157:978-80.

4. Prebeg Ž, Bralić I. Changes in Menarcheal Age in Girls Exposed to War conditions. Am J Hum Biol. 2000;12:503-8.

5. Belsky J, Steinberg L, Draper P. Childhood experience, interpersonal development, and reproductive strategy: An evolutionary theory of socialization. Child Dev. 1991;62:647-70.

6. Ellis BJ. Timing of pubertal maturation in girls: an integrated life history approach. Psychol Bull. 2004; 130:920-58.

7. Draper P, Harpending H. Father absence and reproductive strategy: an evolutionary perspective. J Anthropol Res. 1982;38:255-73.

8. Culpin I, Heron J, Araya R, Melotti R, Lewis G, Joinson C. Father absence and timing of menarche in adolescent girls from a UK cohort: themediating role of maternal depression and major financial problems. J Adolesc. 2014;37(3):291-301.

9. Quinlan RJ. Father absence, parental care, and female reproductive development. Evol Hum Behav. 2003;24:376-90.

10. Moffitt TE, Caspi A, Belsky J, Silva PA. Childhood experience and the onset of menarche: A test of a sociobiological model. Child Dev. 1992;63:47-58.

11. Tither JM, Ellis BJ. Impact of fathers on daughters' age at menarche: a genetically and environmentally controlled sibling study. Dev Psychol. 2008;44(5):1409-20. 
12. Alvergne A, Faurie C, Raymond M. Developmental plasticity of human reproductive development: effects of early family environment in modern-day France. Physiol Behav. 2008;95(5):625-32.

13. Mendle J, Leve LD, Van Ryzin M, Natsuaki MN, Ge X. Associations Between Early Life Stress, Child Maltreatment, and Pubertal Development Among Girls in Foster Care. J Res Adolesc. 2011;21(4):871-80.

14. Webster GD, Graber JA, Gesselman AN, Crosier BS, Schember TO. A life history theory of father absence and menarche: a meta-analysis. Evol Psychol. 2014;12(2):273-94.

15. Ellis BJ, McFadyen-Ketchum S, Dodge KA, Pettit GS, Bates JE. Quality of Early Family Relationship and Individual Differences in the Timing of Pubertal Maturation in Girls: A Longitudinal Test of an Evolutionary Model. J Pers Soc Psychol. 1999;77:387-401.

16. Graber JA, Brooks-Gunn J, Warren MP. The antecedents of menarcheal age: Heredity, family environment, and stressful life events. Child Dev. 1995; 66:346-59.

17. Mekos D, Hetherington EM, Clingempeel WG. Psychosocial influences on the rate and timing of pubertal development. In: Steinberg L (Chair). Psychosocial antecedents of the timing of puberty. Symposium conducted at the biennial meetings of the Society for Research on Adolescence; Washington, DC; 1992.

18. Surbey MK. Family composition, stress, and the timing of human menarche. In: Ziegler TE, Berkovitch FB, editors. Socioendocrinology of primate reproduction. New York: Wiley-Liss; 1990. p. 12-32.

19. Izard MK. Social influences on the reproductive success and reproductive endocrinology of prosimian primates. In: Ziegler TE, Bercovitch FB, editors. Socioendocrinology of primate reproduction. New york: Wiley-Liss; 1990. p. 159-86.

20. Burger J, Gochfeld M. A hypothesis on the role of pheromones on age of menarche. Med Hypotheses. 1985;17:39-46.

21. Ellis BJ, Garber J. Psychosocial antecedents of variation in girls' pubertal timing: Maternal depression, stepfather presence, and marital and family stress. Child Dev. 2000;71:485-501.

22. Comings DE, Muhlemann D, Johnson JP, MacMurray JP. Parent-daughter transmission of the androgen receptor gene as an explanation of the effect of father absence on age of menarche. Child Dev. 2002;73:1046-51.

23. Agency for statistics of Bosnia and Herzegovina, First release. No. 1. Sarajevo; 2013.
24. Agency for statistics of Bosnia and Herzegovina. National accounts, Gross domestic product for 1997-2003. Thematic Bulletin 01, December 2004.

25. Federation of Bosnia and Herzegovina Employment Services. Monthly Statistics Bulletine. 2003.

26. Toromanović A, Tahirović H. Age at Menarche in Federation of Bosnia and Herzegovina. Paediatrics Today. 2010;6(1):36-44.

27. Wierson M, Long PJ, Forehand RL. Toward a new understanding of early menarche: the role of environmental stress in pubertal timing. Adolescence. 1993;28:913-24.

28. Campbell BC Udry JR. Stress and age at menarche of mothers and daughters. J Biosoc Sci. 1995;27:127-34.

29. Bogaert AF. Menarche and father absence in a national probability sample. J Biosoc Sci. 2008;40:623-36.

30. Bogaert AF. Age at puberty and father absence in a national probability sample. J Adolesc. 2005;28:541-6.

31. Hoier S. Father absence and age at menarche: A test of four evolutionary models. Hum Nat. 2003;14:209-33.

32. Hulanicka B. Acceleration of menarcheal age of girls from dysfunctional families. J Reprod Infant Psychol. 1999;17:119-32.

33. McLanahan S, Sandefur G. Growing up with a single parent: What hurts, what helps. Cambridge, MA: Harvard University Press; 1994.

34. Weinraub M, Horvath DL, Gringlas MB. Single parenthood. In: Bornstein $\mathrm{MH}$, editor. Handbook of parenting. Hillsdale, NJ: Lawrence Erlbaum Associates; 2002. p. 109-39.

35. Dunn J, Deater-Deckard K, Pickering K, O’Connor TG, Golding J. Children's adjustment and prosocial behaviour in step-, single-parent, and nonstepfamily settings: findings from a community study. ALSPAC Study Team. Avon Longitudinal Study of Pregnancy and Childhood. J Child Psychol Psychiatry. 1998;39(8):1083-95.

36. Cummings EM, Davies PT. Maternal depression and chiled development. J Child Psychol Psychiatry. 1994;35:73-112.

37. Amato P. Children's adjustment to divorce: Theories, hypotheses, and empirical support. J Marriage Fam. 1993;55:23-38.

38. Hetherington EM, Stanley-Hagan MM. Parenting in divorced and remarried families. In: Bornstein $\mathrm{MH}$, editor. Handbook of parenting. New Jersey, USA: Lawrence Erlbaum Associates; 2002. p. 287315. 
39. Luczak E, Laska-Mierzejewska T. Physical growth of children from alcoholic families. Studies In Physical Antropology. 1990;10:101-11.

40. Wronka I, Pawlinska-Chmara R. Menarcheal age and socio-economic factors in Poland. Ann Hum Biol. 2005;32:630-8.

41. Padez C. Social background and age of menarche in Portuguese university students: a note on the secular changes in Portugal. Am J Hum. 2003;15:415-27.
42. Chavarro J, Willamor E, Narvaez J, Hoyos A. Socio-demographic predictors of age at menarche in a group of Colombian university women. Ann Hum Biol. 2004;31:245-57.

43. Toromanović A, Tahirović H. Age at menarche in the Federation of Bosnia and Herzegovina: effect of socioeconomic status. Horm Res Paediatr. 2010;74(Suppl 3):S192. 